\title{
Indicants of response strength hierarchies in continued word association'
}

BURTON G. ANDREAS

UNIVERSITY OF ROCHESTER

One minute of continued word association was shown to yield both the Noble (1952) and Noble \& Parker (1960) indicant of meaningfulness, $m$, and the Bilodeau $\mathcal{E}$ Howell (1965) indicant of probability of response occurrence. The probability values (proportion of Ss giving particular responses) were determined over the entire period of response production as well as for the initial group of three responses. The median ordinal position of response occurrence was also calculated. The probability values of the present study correlated positively with those obtained by Bilodeau $\mathcal{G}$ Howell. Over the restricted range studied, these $p$ values did not correlate significantly with median ordinal position.

Noble (1952) and Noble \& Parker (1960) allowed a full minute of continued word association to each verbal stimulus item. These studies were directed at determing a scale value of meaningfulness, $\underline{m}$, for each stimulus word or paralog and did not report on the relative frequencies of occurrence of responses. Bilodeau \& Howell (1965) required Ss to give three responses to each of several other stimulus words in their continuing word association technique for identifying response probability hierarchies. Their required termination of the response sequence naturally did not permit a determination of the $\underline{m}$ value for the stimulus word.

The present study employed most of the Bilodeau \& Howell stimuli of five-letter length and CVCVC format, plus three words not on their list but scaled for $m$ by Noble. The aim of the research was to see if Noble's technique could be used to obtain response probabilities comparable to those of Bilodeau \& Howell as well as stimulus $\underline{m}$ values. In addition, the median ordinal position of the common responses was determined to provide additional evidence for the existence of associative response strength hierarchies in verbal behavior.

Method

Thirty-three Army enlisted men and 35 summer session students from the University of Delaware served as Ss. The Army men were volunteers for medical and psychological studies. The students were paid for participation in a series of experiments of which this was the first.

Each stimulus word, of five-letter CVCVC spelling, was arrayed in two double-spaced columns of ten repetitions each on a mimeographed page of a stapled test booklet.

Instructions to Ss were taken verbatim from Noble's (1952, p. 425) report. His procedure was modified by eliminating practice pages and the 15-sec. inter-item interval. No rest period was required due to the brevity of the test administered. The test booklets were assembled with pages randomly ordered, except that stimulus words RIVER and WATER were placed in separate halves of the booklet.

Results

The results of the study are presented in Tables 1 and 2. The $\underline{m}$ value, defined as the mean number of responses (acceptable by Noble's criteria) given to the stimulus in $1 \mathrm{~min}$., is shown with its SD in Table 1 for each stimulus word. The recorded scale values are based on data from the Army men and the college students treated separately. This reporting of two $\underline{m}$ values is felt to be appropriate since the college students were significantly more productive of responses to every stimulus word than were the enlisted men as shown by the $t$ ratios given in the table. This finding is similar to that of Noble \& Parker (1960) who compared two such groups on total productivity over 96 stimulus items.

Response probability data are recorded in Table 2 for the responses found to have the most frequent occurrence as one of the first three responses given by S. Applying this criterion to the Bilodeau \& Howell data and those of the present study separately required the tabulation of four responses in all common stimulus instances due to ties or inversions of probabilities obtained. The Bilodeau \& Howell values were obtained from their compilation by summing across the probabilities they recorded for each ordinal position in the series of three responses they permitted. The adjacent column of probability values represents the proportion of Ss in the present study who gave the response among the first three written. In the next column is the proportion of Ss giving this response at any point in the $1-$ min. period allowed. This $p$ value is thus inclusive of the $p$ value for response positions 1-3.

The final column of Table 2 contains the median ordinal position of each response tabled. The median is here considered more representative than the mean due to skewness of data distribution caused Table 1. Meaningfulness Value $(m)$ and SD for Stimulus Words Given to Military and College Samples. Significant Differences in $m$ Were obtained $(p<.05)$ for Each Word as $t$ Ratios Indicate.

\begin{tabular}{lrrrrr} 
& \multicolumn{6}{c}{33 Enlisted Men } & 35 College Students & \\
Stimulus & $m$ & SD & $m$ & SD & $t$ \\
\hline COLOR & 8.91 & 2.91 & 12.46 & 3.81 & 4.23 \\
MUSIC & 9.03 & 3.03 & 12.57 & 4.25 & 3.87 \\
RIVER & 9.85 & 3.21 & 12.20 & 4.01 & 2.61 \\
WATER & 11.12 & 3.13 & 14.37 & 3.68 & 3.87 \\
WOMAN & 8.33 & 2.98 & 10.20 & 3.14 & 2.47 \\
LEMUR & 3.61 & 3.27 & 8.03 & 4.20 & 4.75 \\
MONEY & 8.39 & 3.64 & 12.14 & 3.94 & 3.99 \\
WAGON & 7.73 & 2.09 & 10.09 & 2.85 & 3.81 \\
\hline
\end{tabular}


Table 2. Probabilities of Occurrence and Median Ordinal Position of the Commonest Responses. $N=68$.

\begin{tabular}{|c|c|c|c|c|c|}
\hline Stimulus & Response & $\begin{array}{l}\text { Probab } \\
\text { B \& H } \\
T-3\end{array}$ & $\begin{array}{r}\text { lities } \\
\text { And } \\
1-3\end{array}$ & $\begin{array}{l}\text { Decurre } \\
\text { as } \\
1-n\end{array}$ & $\begin{array}{l}\text { Medion } \\
\text { Ordinal } \\
\text { Position }\end{array}$ \\
\hline COLOR & $\begin{array}{l}\text { red } \\
\text { blue } \\
\text { black } \\
\text { green }\end{array}$ & $\begin{array}{l}.53 \\
.51 \\
.20 \\
.20\end{array}$ & $\begin{array}{l}.47 \\
.28 \\
.21 \\
.22\end{array}$ & $\begin{array}{l}.63 \\
.60 \\
.41 \\
.51\end{array}$ & $\begin{array}{l}2.42 \\
3.80 \\
3.50 \\
4.13\end{array}$ \\
\hline MUSIC & $\begin{array}{l}\text { song }(s) \\
\text { note }(s) \\
\text { sound }(s) \\
\text { dance }\end{array}$ & $\begin{array}{l}.23 \\
.18 \\
.15 \\
.07\end{array}$ & $\begin{array}{l}.15 \\
.16 \\
.09 \\
.15\end{array}$ & $\begin{array}{l}.21 \\
.28 \\
.21 \\
.40\end{array}$ & $\begin{array}{l}1.50 \\
2.40 \\
3.83 \\
4.38\end{array}$ \\
\hline RIVER & $\begin{array}{l}\text { water } \\
\text { stream } \\
\text { lake } \\
\text { boat }\end{array}$ & $\begin{array}{l}.56 \\
.24 \\
.17 \\
.16\end{array}$ & $\begin{array}{l}.41 \\
.24 \\
.13 \\
.16\end{array}$ & $\begin{array}{l}.62 \\
.31 \\
.18 \\
.60\end{array}$ & $\begin{array}{l}2.20 \\
1.46 \\
2.50 \\
4.45\end{array}$ \\
\hline WATER & $\begin{array}{l}\text { wet } \\
\text { drink } \\
\text { swim } \\
\text { river }\end{array}$ & $\begin{array}{l}.44 \\
.41 \\
.18 \\
.04\end{array}$ & $\begin{array}{l}.15 \\
.40 \\
.12 \\
.22\end{array}$ & $\begin{array}{l}.28 \\
.65 \\
.50 \\
.44\end{array}$ & $\begin{array}{l}2.00 \\
2.30 \\
7.17 \\
3.50\end{array}$ \\
\hline WOMAN & $\begin{array}{l}\text { man } \\
\text { girl } \\
\text { wife } \\
\text { sex }\end{array}$ & $\begin{array}{l}.47 \\
.36 \\
.25 \\
.21\end{array}$ & $\begin{array}{l}.35 \\
.25 \\
.16 \\
.32\end{array}$ & $\begin{array}{l}.44 \\
.32 \\
.28 \\
.53\end{array}$ & $\begin{array}{l}1.39 \\
2.00 \\
3.20 \\
2.70\end{array}$ \\
\hline LEMUR & $\begin{array}{l}\text { animal } \\
\text { lemon } \\
\text { French }\end{array}$ & $\begin{array}{l}-- \\
-- \\
--\end{array}$ & $\begin{array}{l}.26 \\
.22 \\
.07\end{array}$ & $\begin{array}{l}.26 \\
.32 \\
.12\end{array}$ & $\begin{array}{l}2.00 \\
2.83 \\
2.17\end{array}$ \\
\hline MONEY & $\begin{array}{l}\text { dollar }(\mathrm{s}) \\
\text { rich } \\
\text { green } \\
\text { coin }\end{array}$ & $\begin{array}{l}-- \\
-- \\
-- \\
--\end{array}$ & $\begin{array}{l}.21 \\
.16 \\
.12 \\
.12\end{array}$ & $\begin{array}{l}.34 \\
.31 \\
.26 \\
.22\end{array}$ & $\begin{array}{l}2.25 \\
3.40 \\
4.50 \\
3.33\end{array}$ \\
\hline WAGON & $\begin{array}{l}\text { wheel } \\
\text { train } \\
\text { covered }\end{array}$ & $\begin{array}{l}-- \\
-- \\
--\end{array}$ & $\begin{array}{l}.62 \\
.32 \\
.25\end{array}$ & $\begin{array}{l}.76 \\
.41 \\
.44\end{array}$ & $\begin{array}{l}1.37 \\
1.80 \\
3.17\end{array}$ \\
\hline
\end{tabular}

occasionally by the very late appearance of a common response in the production of one or two Ss.

Pearson product-moment correlation coefficients were computed as indicants of strength of agreement between several of the pairs of measures of response strength. Over the limited range of the high $p$ values examined, the correlation of the probability of occurrence in the first three responses of the present study with the corresponding $p$ values from Bilodeau \& Howell (1965) was $r=+.724$ for the 20 responses of Table 2 . When the present study's pairs of pvalues (for Positions $1-3$ and $1-n$ ) were correlated, $r$ was found to be +.782 . The correlation of $p$ values for Positions $1-n$ in the present study and Bilodeau \& Howell's p values was +.424 . When $\mathrm{p}$ values for Positions $1-n$ were correlated with the median ordinal position for responses of this experiment, $r$ was +.098 , not significantly different from zero.

\section{Discussion}

The results tabulated in Tables 1 and 2 demonstrate the feasibility of using $1-\mathrm{min}$. of continuing word association to obtain both the $\underline{m}$ value which describes the stimulus items' meaningfulness and the p values indica- tive of associative response strengths. This joint determination of descriptive values represents an economy over the separate approaches of prior investigations.

The correlation of present data with the $p$ values of Bilodeau \& Howell is sufficiently high, in the light of restricted range and possible subject population differences, to suggest that the present practice of allowing responses beyond the first three tabulated is acceptable. The Bilodeau and Howell interest in the first three responses can be satisfied even if subjects go on to give several more in the minute allowed.

The correlation between $p$ values for Positions 1-3 and $1-n$ is not surprising in view of the fact that the latter set of responses contains the former. The lower correlation of the present $p$ for Positions $1-n$ with Bilodeau \& Howell's p values suggests that going on to permit additional responses uncovers different facets of response strengths than when responding is terminated with only three responses permitted.

The lack of significant correlation of median ordinal position with $\mathrm{p}$ values over the restricted range examined suggests that this separate index of response strength may be useful in describing response tendencies of subjects, apart from their propensity to give the same early responses. Over a greater range of responses given, we might expect this correlation to become significantly negative, with less frequent responses occurring later in the series. However, for the most common responses, the median ordinal position appears to yield a different sort of information from the $p$ value. For example, the response boat to RIVER occurs a couple of response positions later than water even though given about as frequently when all $\mathbf{n}$ responses are tallied. To stimulus MUSIC, dance is given more frequently than other responses though it tends to be given somewhat later as Table 2 shows. This demonstrates the descriptive utility of adding median ordinal position of response to the $\underline{m}$ value and the $p$ values when using continuing word association to explore response strength hierarchies.

In view of the demonstrated economy of multiple scaling of verbal stimuli and responses with the method employed here, it is felt that the approach should now be used to provide a larger pool of such scaled materials for use in verbal learning, memory, and perception experiments.

\section{References}

Bilodeau, E. A., \& Howell, D. G. Free association norms by discrete and continued methods. Washington, D. C.: Office of Naval Research, 1965.

Noble, C. E. An analysis of meaning. Psychol. Rev., 1952, 59, 421-430.

Noble, C. E., \& Parker, G. V. C. The Montana scale of meaningfulness ( $m$ ). Psychol. Rep., 1960, 7, 325-331.

\section{Note}

1. This study was conducted while the author was Distinguished Visiting Professor at the Supporting Research Laboratory, U. S. Army Human Engineering Laboratories, Aberdeen Proving Ground, Maryland. The cooperation extended by Dr. John D. Weisz, Chief, and members of his staff is gratefully acknowledged. 